IZA DP No. 8061

The Two-Step Australian Immigration Policy and its Impact on Immigrant Employment Outcomes

Robert G. Gregory

March 2014 


\title{
The Two-Step Australian Immigration Policy and its Impact on Immigrant Employment Outcomes
}

\author{
Robert G. Gregory \\ CSES, Victoria University, \\ Australian National University and IZA
}

Discussion Paper No. 8061

March 2014

IZA

P.O. Box 7240

53072 Bonn

Germany

Phone: +49-228-3894-0

Fax: +49-228-3894-180

E-mail: iza@iza.org

Any opinions expressed here are those of the author(s) and not those of IZA. Research published in this series may include views on policy, but the institute itself takes no institutional policy positions. The IZA research network is committed to the IZA Guiding Principles of Research Integrity.

The Institute for the Study of Labor (IZA) in Bonn is a local and virtual international research center and a place of communication between science, politics and business. IZA is an independent nonprofit organization supported by Deutsche Post Foundation. The center is associated with the University of Bonn and offers a stimulating research environment through its international network, workshops and conferences, data service, project support, research visits and doctoral program. IZA engages in (i) original and internationally competitive research in all fields of labor economics, (ii) development of policy concepts, and (iii) dissemination of research results and concepts to the interested public.

IZA Discussion Papers often represent preliminary work and are circulated to encourage discussion. Citation of such a paper should account for its provisional character. A revised version may be available directly from the author. 


\section{ABSTRACT \\ The Two-Step Australian Immigration Policy and its Impact on Immigrant Employment Outcomes ${ }^{1}$}

Three decades ago most immigrants to Australia with work entitlements came as permanent settlers. Today the annual allocation of temporary visas, with work entitlements, outnumbers permanent settler visas by a ratio of three to one. The new environment, with so many temporary visa holders, has led to a two-step immigration policy whereby an increasing proportion of immigrants come first as a temporary immigrant, to work or study, and then seek to move to permanent status. Around one half of permanent visas are allocated onshore to those who hold temporary visas with work rights. The labour market implications of this new two-step system are substantial. Immigrants from non-English speaking countries (NES), are affected most. In their early years in Australia, they have substantially reduced full-time employment and substantially increased part-time employment, usually while attending an education institution. Three years after arrival one third of NES immigrants are now employed part-time which, rather than unemployment, is becoming their principal pathway to full-time labour market integration. Surprisingly, little has changed for immigrants from English speaking countries (ES).

JEL Classification: J15, J61, J68, F22

Keywords: immigrant part-time employment, fee paying foreign students, temporary employment visas, labour market integration

Corresponding author:

Robert G. Gregory

Research School of Economics

Australian National University

Canberra, ACT

Australia, 0200

E-mail: bob.gregory@anu.edu.au

\footnotetext{
${ }^{1}$ R. J. Bray, M. Cully and members of the Department of Immigration and Border Protection have helped a great deal, especially in finding my way around so many different immigration data concepts. I would like to dedicate this paper to Paul Miller, one of my early doctoral students and a wonderful researcher and teacher.
} 


\section{The Two-Step Australian Immigration Policy and its Impact on Immigrant Employment Outcomes}

\section{Introduction}

During the 1980's and 1990's, the Australian immigration program was built on two pillars; a planned annual intake of permanent settlers - skilled, family and humanitarian migrants - and an increasingly sophisticated points system to select skilled immigrants with high quality labour market attributes that easily transfer to the local labour market. The program was tightly controlled by government regulation and discouraged employment of temporary migrants. Immigrants seeking to live and work in Australia typically applied for permanent residence off-shore and, after receiving a visa, arrived and began to search for employment, often reporting unemployment rates of 20-30 per cent during their first six or so months after arrival.

Over the last two decades, the immigration process has begun to change in a far reaching way that is fundamentally impacting on the selection of immigrants, the labour market integration process and the nature of the immigrant work force. The permanent immigration process has been evolving into a partial two-step policy framework. ${ }^{2}$

The first step in this new framework is for skilled, or potentially skilled migrants to obtain temporary immigrant status to work or study. The numbers who take the first step are uncapped and lightly regulated. The second step is to use skilled employment and/or study in Australia, under a temporary visa, to demonstrate high quality and needed labour market skills and, in this way, strengthen qualifications for permanent residence status via the skilled migrant stream that now accounts for 60 per cent of permanent migrant places. The temporary migrant, seeking a permanent visa, may apply as an independent skilled applicant recent Australian skilled work experience or completion of an Australian qualification adding to their points total - or, as is more common, apply through employer sponsorship, not subject to a points test, but requiring an employer submission that an Australian citizen cannot be found for the skilled vacancy (DIAC, 2011, Hawthorne 2011). The numbers who successfully complete the second step are capped and more tightly regulated.

From our perspective, the two essential features of a two-step policy are that it widens the time gap between immigrant arrival and permanent visa status and creates a large pool of temporary migrants with work entitlements, not all of whom will subsequently acquire permanent status. These two features will have a substantial impact on settler selection criteria and pathways to permanent settlement. They will also significantly affect relationships between recent migrants and the Australian economy. If these effects are substantial, the two-step policy will require a change in the standard analytical framework used to assess immigrant labour market integration. So how important has the two-step process become?

\footnotetext{
${ }^{2}$ A two-step policy is also being developed in New Zealand and Canada although the details and design naturally varies (Hawthorne, 2011). In NZ, 83 per cent of permanent resident visas for skilled migrants are granted on-shore (Hawthorne, 2011)
} 
It is evident that a large pool of temporary immigrants, with work entitlements, has been created. This pool probably now accounts for three quarters of a million potential workers who, if all were employed, would be seven per cent of Australian aggregate employment. ${ }^{3}$ By way of contrast, annual permanent visa inflows, if all were employed, would account for just under two per cent of Australian employment.

The impact of this large pool of temporary migrants on the pathway to a permanent visa has been very significant. One third of permanent resident visa holders in Australia at Nov 2010, who arrived in the previous decade, reported to the Labour Force Survey that, in the first instance, they held a temporary resident visa (ABS, 2011). More recent administrative data indicate that around 50 per cent of permanent resident visas are now granted on-shore to those who held a temporary visa with work entitlements (DIAC 2013). ${ }^{4}$ For skilled migrants this proportion currently fluctuates around 70 per cent.

The growth of a large temporary migrant pool has also led to additional and more stringent labour market selection criteria to be applied to on-shore permanent visa applicants. Additional selection criteria have included Australian employment - location and occupation - and Australian education and skill qualification attainment. More stringent criteria for onshore permanent visa success have also flowed over to higher education and employment requirements for off-shore applicants.

The effects of more stringent visa requirements are clearly observed among new settlers. The increased emphasis on a strong employment record is evident in the 2009 allocation of permanent visas. Among the $77 \%$ of skilled migrants (principal applicants and partners from the temporary migrant pool), who successfully applied on-shore for a permanent visa, 92 per cent were employed at the time of permanent visa acquisition. Among the 23 per cent of skilled permanent visa immigrants, who successfully applied for a permanent visa off-shore, the employment rate within a few months after arrival was 87 per cent (Table 1 and Table 7 , DIAC, 2010). Among all permanent visa recipients, including those arriving under the family stream, the employment level has been around 72 per cent (Table H1, DIAC, 2012). The employment rate, for native born Australians 15 years and over, is a lower 62 per cent.

Higher education qualifications, which facilitate employment, have also lifted; in 2009, 53 per cent of all new permanent visa recipients possessed a Bachelor's degree or above. Among the skilled migrant intake the ratio is 66 per cent (Table 1, CSAM 2011). These are phenomenal employment and education outcomes among new permanent settlers.

As the nature of new permanent settlers changes - higher employment incidence, higher education qualifications, larger time gap between arrival and permanent visa receipt - they become less representative of the total immigrant inflow, most of which now arrive on a temporary visa with work entitlements. Furthermore, if the temporary migrant pool continues to grow more quickly than the permanent visa "quota", then, during the first five or so years

\footnotetext{
${ }^{3}$ These calculations exclude New Zealanders who can enter and work in Australia without a visa.

${ }^{4}$ For 1990-91, 11 per cent of permanent resident visa allocations were granted on-shore (DIAC, 2013).
} 
after arrival, new migrants, after receiving permanent status, will make a smaller and smaller contribution to labour market outcomes of all new migrant inflows, simply because the time period between entry to Australia and receiving a permanent visa is lengthening. Under these circumstances, to assess policy change effects, and to measure recent immigration inflow contributions to the Australian economy, it is essential to include all new immigrants in the analysis, and not only new permanent settlers. It is also important to be able to follow, in detail, the rapidly changing labour market outcomes within the first five years or so after arrival and to link labour market outcomes to visa category. These seem straightforward tasks but pose quite serious data challenges.

To assess labour market effects of immigrant policy changes it has been usual to use survey data collected by the Department of Immigration (DIAC 2012). The Longitudinal Survey of Immigrants to Australia (LSIA) and The Continuing Survey of Australian Migrants (CSAM), are the only data sources that link employment outcomes to visa type. These data, however, only include new permanent visa recipients and are focussed on principal applicants. ${ }^{5}$ The larger number of temporary migrant arrivals is excluded. Furthermore, labour market outcomes for new permanent settlers, during their time on a temporary visa, are also excluded from the surveys. The immigration department data also have another major disadvantage. The surveys usually consist of two or three cross-section snapshots at the most; labour market outcomes just before or at the point of permanent visa allocation and outcomes twelve or eighteen months later. These snapshots cover a very short period of time. Thus, official surveys of permanent settlers, at time of permanent visa receipt, are becoming less representative of aggregate migrant inflows and provide little data as to the change in labour market experiences in the early years after arrival but before acquiring permanent visa status. ${ }^{6}$

There has been some analysis of immigrant integration based on a different data source, the Australian census. These data extend beyond new permanent settlers and include all immigrants, but does not collect visa status (Chiswick and Miller, 2013, McDonald and Worswick, 1999). The major limitation, however, is that the Census is taken only once each five years and most of the detailed data that can be utilized on a unit record basis are not released until three or so years after collection. Hence, over a decade of large changes, there may be only two snapshots of the changing migrant pool that can capture the effects of the evolution of a new policy regime. There is also another problem. Time of arrival data is grouped in coarse five year intervals which cannot be used to analyse the changing immigrant labour market outcomes for each year within the crucial early years after arrival.

\footnotetext{
5 About 40 per cent of visa allocations are taken by non-principal applicants, that is family members.

6 The Longitudinal Survey of Immigrants to Australia (LISA) - consists of three cohorts 1993-95, 1999-2000 and 2005-06. The cohorts are interviewed two or three times, usually at arrival and six and eighteen months later ((Cobb-Clark (2003), (2004), Junankar, Paul and Jasmeen, (2010)). This survey does not include students or temporary business immigrants. The two early cohorts were confined to those who were part of the permanent migration program and had applied for permanent resident status offshore. The surveys therefore excluded the fifty per cent or so of migrants who applied for permanent status on-shore and were part of the two-step process. The Continuous Survey of Australia's Migrants, began in 2009 and now consists of five independent waves. It collects a new sample of recently arrived migrants who have received permanent residence status or are on the way to doing so (DIAC 2012). The survey interviews each cohort six and twelve months after arrival. There is no systematic coverage of temporary migrants. Neither survey covers employment outcomes over a long period.
} 
Inadequacies of these two major data sources are becoming increasingly serious as the temporary immigrant data pool increases and the nature of recent arrivals changes. What can be done? Perhaps the best short run response is to turn to the monthly Labour Force Survey which has not been significantly exploited in the Australian immigrant literature. This survey casts a much wider immigrant net than the official survey of permanent visa recipients, and, as with the Census, all migrant employment is linked to arrival date and not to the date of permanent visa acquisition. ${ }^{7}$ The Labour Force Survey data, however, do not include wage variables and are not generally available on a unit record basis and also do not link employment to visa category. However, the data possess a unique feature that has become increasingly important as the two-step process has strengthened and the pool of temporary immigrants increased.

The unique feature is that the Labour Force collects immigrant labour market outcomes month-by-month after arrival. Cohorts more precisely defined by arrival dates than in the five yearly Census can be followed month-by-month. This time series feature - pseudo cohort data collected monthly - will be especially useful in analysing monthly employment outcomes in the early years after arrival when the temporary-permanent visa distinction is so important.

The results, obtained from exploiting this unique feature of the Labour Force Survey, are very different from those found in new permanent settler data. They bring out labour market relationships that cannot be captured in the coarse arrival intervals of the five yearly Census snapshots. The marked differences in results underline the need for a re-orientation of the immigrant labour market integration discourse. For ease of exposition, in this paper, we focus on male outcomes but there is an accompanying paper directed towards female immigrants where the results are also different from those derived from other data sources (Gregory, 2014).

Unlike the permanent settler surveys, the monthly Labour Force data do not indicate a spectacular employment lift among all newly arrived immigrants in response to the immigration reforms of the 1990s as suggested by the permanent settler analysis of CobbClark 2003, 2004. Indeed, employment incidence is lower over the first five or so years after arrival than before the two-step policy evolved. These employment falls are concentrated upon migrants from Non English Speaking countries (NES). Later we conjecture as to why this has occurred.

The Labour Force data also reveal a growing importance of the distinction between full and part-time employment and reveal how part-time employment has become an integral part of the labour market integration experience of new migrant. ${ }^{8}$ Among most recent NES cohorts,

\footnotetext{
${ }^{7}$ The Labour Force Survey covers .032 per cent of the civilian population 15 years and over. For preliminary analysis using these data to map changing migrant employment see Shah and Burke (2005), Birrell and Healy (2013).

${ }^{8}$ In terms of policy interest, the analysis of wage integration has been relatively unimportant in Australia as migrants, on average, earn more than the native born and consequently wage "catch-up" is not usually thought of as a major issue. English language facility, however, does affect labour market outcomes and for the NES group it appears that wages begin at lower levels that the native born and increase with time spent in Australia but there seems little consistency in the size of the estimated results (ABS, 2006, Antecol et al, 2003, Chiswick and Miller, 2013, Breunig et al, 2013)). The estimates of wage catch-up vary a great deal by data source.
} 
part-time employment, three or four years after arrival, is almost as important as full-time employment. Overwhelmingly, NES migrant integration into the full-time labour market now takes place via part-time employment rather than via the unemployment pool. This new feature of migrant early years in the temporary migrant pool is missed by an analysis that focusses only on those who receive a permanent visa, often many years after arrival. The growing importance of part-time employment in the labour market integration process is largely missed in the five year census snapshots, partly because the data reflect outcomes of previous decades and partly because arrival cohorts are grouped in coarse five year intervals.

Changing labour market outcomes, in response to the two-step visa system, point to the need to adapt the traditional methodology applied to assess changing immigrant labour quality and labour market integration across cohorts (Chiswick, 1978, Borjas, 1985). The traditional model, which is most appropriate when immigrants arrive as permanent settlers, is increasingly at odds with the new environment where the typical new arrival is a temporary migrant who is likely to leave within a few years. An uncritical application of the traditional model to assess labour market integration would compare labour market outcomes of the average immigrant in a new arrival cohort, most of whom will not achieve permanent status, with labour market outcomes of the average immigrant of an older cohort, all of whom are permanent settlers. The data would be analysed as if they represented the longitudinal experience of a pseudo cohort.

The increasing passage of time between arrival date and permanent settler status, generated by the two-step policy, will increasingly confound estimates of the changing rate of assimilation and cohort quality. To illustrate the problem suppose, for example, if, in response to a policy change, a large number of migrants arrive on a temporary visa to study full-time at an education institution and their labour market experience is effectively limited to part-time employment in low paying service sector jobs. ${ }^{9}$ Under these circumstances, the traditional labour market integration analysis may suggest that the labour market quality of recent immigrant cohorts has fallen - lower employment rates and lower wages - whereas the inherent labour market quality of the permanent immigrant intake - selected some time later when tertiary courses are completed and well-paid full-time jobs obtained - may appear to have increased considerably.

Application of the traditional model, confined to an analysis of the changing labour market integration of permanent settlers, will also become increasingly unsatisfactory. As the time gap lengthens, between the first labour market involvement, usually as a temporary migrant, and receipt of a permanent visa, an increasing share of the labour market integration process for a permanent settler will occur before receiving a permanent visa and this experience is not collected in the permanent settler data base. Labour market quality of permanent immigrants may seem to improve, because employment is increasing at the time of permanent visa receipt but this outcome may be due to unmeasured and increasing labour market experience before becoming a permanent settler.

\footnotetext{
${ }^{9}$ Student visas include a condition that once the course is commenced the student is restricted to forty hours paid labour market work per fortnight during the education semester.
} 
The remaining sections of the paper take these ideas and immigration outcomes and develop them in more detail. Part II provides a brief background description of Australian immigration policy history, the data and the methodology applied. Part III focuses on the empirical analysis of male immigrant labour market outcomes and their relationship to timesince-arrival. Part IV discusses the two-step policy and the shifting full- and part-time employment relationships. Part V offers concluding comments.

\section{Background, Data and Methodology}

Immigration inflows are a crucial macro-policy instrument in Australia. Annual permanent immigrant inflows have varied between 5 and 70 per cent of the annual population growth over the last half century. Immigration targets were set at historically low levels in the late 1970s but since then have increased considerably. Over the last three decades, new male migrants have accounted for fifty per cent of the total increase in male full-time employment and twenty-five per cent of the increase in male part-time employment. The evolution of the Australian labour market cannot be fully understood without being aware of the changing nature of male immigrant employment integration.

The immigrant system is complex but, for our purposes, it can be simplified into two parts: a system of temporary visas and a system of permanent visas. Temporary visas, with work rights, were insignificant three decades ago but now their annual allocation far exceeds that of permanent visas. The allocation of temporary visas with work entitlements, was 679 thousand over 2011-12. The allocation of permanent visas was 202 thousand. ${ }^{10}$

It is not possible to precisely link particular immigration policy changes to particular labour market outcomes. Policy rarely proceeds in large steps, but continually evolves, and, as indicated earlier, data that directly link changes in visa allocations and visa conditions of all immigrants to labour market outcomes are not available.

In this environment the methodology to evaluate policy change effects, by necessity, must be very simple. The approach adopted here is to describe, throughout the last three decades, monthly labour market employment and unemployment outcomes for cohorts of male immigrants as the time in Australia lengthens. Then, once observed changes are clearly documented to discuss whether these changes can be attributed to the two-step policy evolution. For this purpose, it is useful to divide the last three and a half decades into two policy regimes, an old and a new regime.

\subsection{Old Regime}

The old regime encompasses the 1980s and the early 1990s when most skilled migrants obtained permanent residence on the basis of the "points system". Immigrants needed to obtain a minimum level of points allocated on the basis of age, English ability, occupation, employment experience and education qualifications (Miller, 1999). Temporary visas were

\footnotetext{
${ }^{10}$ The permanent visa system can be divided into three parts; skilled immigration, family reunion and humanitarian. Skilled immigration is increasing in importance and family reunion decreasing. For 2011-12, permanent residency visas were allocated 65 per cent skilled, 28 per cent family and 7 per cent humanitarian.
} 
small in number and the pathway from temporary visa to permanent residence was unimportant. Most permanent visas were allocated to off-shore applicants.

\subsection{New Regime}

The new regime encompasses the decade and half after 2000. Over this period, temporary visas, with work rights, have grown quickly. In response, the allocation of permanent visas on-shore to those with temporary visas, and living in Australia, has become increasingly important. The two-step process has become the most common pathway to permanent residence.

Step one is primarily built around two temporary visa categories; fee paying international students (potentially skilled) and business sponsored temporary full-time employed skilled migrants (these visas are officially referred to as long-stay visas but are limited to a maximum of four years stay) ${ }^{11}$. Student visas allow a full-time student to work up to 20 hours a week and unlimited time during semester breaks. Business sponsored visas (457's) are for full-time employment and lapse if employment is terminated but can be reinstated, subject to immigration department approval, if the visa conditions can be met with another employer. Each of these temporary visas are uncapped and largely removed from detailed government control, although broad conditions must be met. Tertiary institutions determine foreign student numbers and their academic requirements. Individual employers determine the migrant inflow they will employ to meet labour market skills that they need and which they argue are not easily found among native workers. ${ }^{12}$

Step two - acquiring permanent status - usually differs between the two temporary visa groups. Business temporary visa holders usually proceed to permanent status within a couple of years usually with the sponsorship of their employer. Students usually apply for another temporary visa after graduation - the bridging visa - which gives them the right to work fulltime for two years after which they may apply for permanent residence either as an individual, through the general skilled points system (their major entry route), or with employer sponsorship which has a higher processing priority and is growing in importance but is still relatively unimportant for them (DIAC, 2013). Over 2011-12, 60 per cent of the successful skilled permanent migration applications were drawn from these two programs.

Permanent residence places are capped (under tight government control). Temporary visas (largely demand driven) are uncapped. The balance between the two largely determines the probability of obtaining permanent residence in the second step process.

\footnotetext{
${ }^{11}$ In September 2013 there were 342,000 students, and 40,000 graduates on temporary visas and 175,000 people on business sponsored (class 457) visas. In addition there were 145,000 young people on working holiday visas and 140,000 on bridging and other visas.

12 A short history of these programs is as follows: (i) study to residency route. In 1985 Australia switched from an "aid to a trade" approach to foreign students (Jackson, 1984) which allowed tertiary institutions to charge full-fees to foreign students. Since then tertiary fee-paying student visa issued during a year have increased from one thousand to more than three hundred thousand. Government controls include a base level English requirement. (ii) work to residency route. Firms could always bring skilled workers to Australia for short periods of time but the program was relatively small. A decade and a half ago the government introduced a 457 visa scheme for these immigrants and delegated quality control and numbers to the business community. There are government imposed conditions to ensure that migrants are of high quality and are filling a labour market gap that cannot be filled by native labour. These visas, allocated during a year, now account for over one hundred thousand workers. Employees on 457 visas have a minimum pay rate of $\$ A 53,900$ per year compared to the Australian Minimum Wage of $\$ 32,350$ (\$A16.37 per hour).
} 
In the long-run, a two-step policy should improve labour market integration of permanent settlers, as measured by employment take-up. Most skilled immigrants obtain permanent residence either after they are brought directly to Australia, already employed, or after buying an Australian education to facilitate their permanent residency application. The substantial on-shore investment in labour market skills by temporary migrants, before obtaining a permanent residence visa, has increased rapidly over the last two decades. This investment should pay-off in the long run in terms of increased employment rates and earnings. Furthermore, there is probably improved selection as temporary migrants "try out" Australia to see whether it suits before taking step two.

In the short-run, a two-step policy, which increasingly generates a large pool of temporary workers confined to the early years after arrival, complicates the analysis of immigrant labour market integration. There are two opposing forces at play.

Immigrants, who arrive as students, will usually delay labour market entry and, while studying, may accept convenient, but low paying, part-time jobs. Labour market integration may appear to deteriorate during the early years after arrival. After course completion, when students enter the labour market on a full-time basis, labour market integration may suddenly appear to substantially improve.

Immigrants, who arrive already employed under a business immigrant skill program, will have the opposite short-run effect on assimilation estimates. There will be almost instant short-run employment integration and labour market quality of new arrivals will appear to increase.

How these two offsetting forces have evolved through time and impacted on immigrant assimilation is yet to be adequately examined.

\section{Empirical Analysis}

In the absence of wage data we focus on immigrant employment. This is a good way to proceed as employment outcomes have always been a major criterion for assessing immigrant policy effectiveness in Australia and wage differences between immigrants and natives are not large (Chiswick and Miller, 2013). Indeed average earnings are higher for immigrants.

Figure 1 plots the evolution, since arrival date, of two immigrant male cohorts, twenty years apart, one cohort from the old regime, 1981-85, and one cohort from the new regime, 200105. ${ }^{13}$ The vertical axis measures the immigrant total employment-population ratio for those over 15 years of age. The horizontal axis measures the period of time since the first month of cohort arrival. The data extend over a maximum of 10 years to avoid the influence of the 1992 recession which impacts adversely on the 1981-85 inflow. Australia largely avoided

\footnotetext{
13 Australian Bureau of Statistics, Labour Force Data Cube LM7, Labour Force Survey by Sex, Country of Birth, Year of Arrival, State. The arrival cohort 1981-85 is the first complete cohort available in the data. The 2001-05 cohort also enables us to analyse employment outcomes over ten years. We will discuss outcomes for the latest cohort, 2006-10, subsequently.
} 
the effect of the Global Financial Crisis and therefor employment outcomes for the 2001-05 inflow are largely unaffected by economic downturns.

Under the old regime, 1981-85, 40 per cent of those who arrived in January 1981 - the peak summer holiday month - responded to the Labour Force Survey of that month that they were employed. This seems a remarkable integration record, one which Australian born university graduates, or school leavers from the previous year, do not achieve in the following January.

Within nine months of arrival, the employment-population ratio increased to the mid $60^{\text {' }} \mathrm{s}$ (the average outcome for those who arrived sometime between January and Sept 1981). From this point onwards, employment primarily fluctuates around 65 per cent until the four year mark, and then increases marginally to plateau for a while at 70 per cent and then increases again eight years after arrival to just under 80 per cent. These data suggest that most employment integration, under the old regime, takes place within a few months after arrival.

Under the new regime, 2001-2005, employment outcomes are different. Comparisons between the two regimes suggest three distinct periods; (i) new regime employment is markedly lower in the early period after arrival, approximately 25-30 per cent, over the first two years and just under 10 per cent lower, on average, over the next two years (ii) from four to six years employment rates are similar across the regimes (iii) after six years, new regime employment moves marginally above old regime employment.

These comparisons prompt two remarks.

First, a routine application of the standard Chiswick/Borjas immigrant labour market integration model to the first four years data after arrival would imply, other things being equal, that immigrant labour market quality has fallen. But there are problems with this interpretation. How is it possible, if new regime immigrant labour market quality is lower, for complete employment catch-up to old regime levels to occur just after the four year mark? Furthermore, the existence of a cross-over around the six year point, after which new regime employment is marginally higher than old regime employment, suggests higher longer term labour market quality of the new regime inflow. There are obvious intertemporal issues at play that need to be taken into account and which complicates a standard type analysis.

Second, the shift of employment patterns across regimes is consistent with expected outcomes from a movement towards a two-step policy in which the effect of foreign student visa growth dominates that of business visa growth, with the result that employment is depressed, in the short run, when students are studying. In the long run, students complete their studies, and, as a result of their education investment, employment begins to increase. Is this a correct way to interpret employment differences across regimes? It is not easy to answer this question when there are no data that link visa category to employment changes through time. But there is an indirect way of proceeding that may help. 
Labour Force data classify immigrants by country of birth. The two major groups are those born in "Main English-speaking countries" (here referred to as English speaking, ES) and those born in "Other than Main English-speaking countries" (here referred to as non-English speaking, NES). The NES proportion of total inflows over a five year period has increased over the last three decades from 50 to 67 per cent.

The large and fast growing fee paying foreign student population is drawn primarily from NES countries, such as China and India, and there is a negligible proportion of ES students, drawn from countries such as the UK, Canada and the USA. In May 2010, NES immigrants accounted for 70 per cent of all foreign born students, 15-19 years and 87 per cent of all foreign born students, 20-34 years (Table 1 Appendix 1, ABS, 2010). By way of contrast, the business visa group is predominantly drawn from ES immigrants. ${ }^{14}$

Since the NES proportion differs so much across these two major visa categories we can use the ES-NES division, in a rough way, to isolate the short run effects of increased student numbers, acting to decrease NES employment, and increased short-term business visas, acting to lift ES employment. Figure 2 presents old and new regime total employment-timesince-arrival relationships for each immigrant group and the results are striking.

First, in both regimes ES immigrants integrate into employment quickly - 75 per cent are employed within six months or so after arrival and then, within three or so years, the employment rate gradually drifts upwards to between 80 and 90 per cent.

Second, in both regimes, NES employment is significantly lower than ES employment and labour market integration is slower. Over the first four years after arrival, NES employment is 30-40 per cent lower than ES employment. The large ES-NES employment gap begins to narrow after four years and convergence between the two groups is almost achieved ten years after first arrival. The employment gap between the two groups is very significant. Over 10 years, the 1981-85 ES inflow was employed an average of 8 years. The NES group were employed three years less.

Third, and this is the surprising, new, and important fact. Within each immigrant group there are only marginal changes in the employment-time-since-arrival relationship between regimes. Despite the growth in skilled short-term business visas there seems to be no significant short-term lift in new regime ES employment. Despite the rapid growth of student numbers there is only a small short term downward movement in new regime NES employment.

The very small total employment changes, within each immigrant group (Figure 2), have an important implication. It indicates that the principal reason for the short term downward movement of aggregate immigrant employment between regimes in the early years after

\footnotetext{
${ }^{14}$ However, the NES proportion is growing within the business category and consequently the skilled worker temporary visa category is not as homogeneous as the student visa category. It also should be remembered that some ES and NES immigrants may have obtained permanent residency under other programs (family re-unions, humanitarian and so on) but they cannot be separated in the data. We doubt, however, whether this will significantly affect the results of this broad brush analysis.
} 
arrival, (Figure 1), is the increase in the inflow proportion of NES migrants, the group with the lowest employment level, rather than a change in total employment behaviour within each group. This fact, considered in isolation, would suggest that the two-step policy change is not important in terms of macro employment outcomes. What matters is the changing proportion of ES and NES immigrant inflows.

But, is this the complete story? Perhaps, in terms of assessing the impact of the two-step policy, total employment is not the right variable to focus on? Perhaps, for example, it would be better to analyse the change in full- and part-time employment separately? There are two reasons why this might be a good idea.

One reason is that students who seek employment while studying are limited to doing so on a part-time basis, and it is possible, for the NES group, that a lift in part-time employment, while studying, more-or-less offsets a fall in full-time employment so that the two-step process has a major effect on the part- full-time employment split but no effect on total employment in aggregate. If this were true there would be a major change in the nature of the immigrant labour market integration process that was not detected by a total employment focus.

There is another important reason for looking at the part- and full-time employment division, and its relationship to increased student enrolments and their impact on labour market integration. Thinking of a large proportion of NES immigrants as temporary, arriving as students and making a major contribution to part-time employment, leads in different policy directions and to different understandings of the nature of current immigration flows than thinking of NES immigrants as permanent and primarily contributing to full-time employment. If the part- and full-time employment dichotomy is important it leads to the need for a new paradigm that is quite different from the usual immigrant permanent-settler paradigm that has been dominant for so long.

\section{The Two Step Policy and the Shifting Full- and Part-Time Employment Relationships}

Figure 3 presents full-time employment-time-since-arrival data for the two inflow groups from each regime. Once again ES full-time employment outcomes differ little between regimes, although old regime ES migrants do perform marginally better during the first eighteen months. The full-time employment relationship through time, and across regimes, seems almost identical with the stability of the total ES employment relationship across regimes (Figure 2). Hence, by implication, there has been little change in ES part-time employment. Labour market integration of ES immigrants, measured by employment outcomes, either full-, part-time or total, has been little affected by the business temporary visa innovation and the two-step process.

For NES migrants, the group most affected by student visa growth, there are noticeable and large full-time employment differences between old and new regimes. Over the first six years, new regime full-time employment is 30 to 60 per cent less than that of the old regime, 
a fall consistent with a substantial student two-step policy effect. Over most of the first six years, in the new regime, only one third of NES male immigrants have a full-time job.

In the longer term, NES full-time employment in the new regime lifts from these very low levels and the full-time employment gap between regimes begins to close until it has disappeared by the ten year mark. It is particularly interesting to note, however, that despite the heavy investment in on-shore education and labour market experience new regime fulltime employment does not exceed old regime full-time employment even after ten years.

Figure 4 presents part-time employment-time-since-arrival outcomes for both immigrant groups. Under the old regime, there was little part-time work and no significant difference between ES and NES migrants. The average part-time employment-population ratio over the ten year period after arrival was just under 5 per cent.

Under the new regime, the situation is quite different. Over the decade after arrival, there is a clear upward movement in part-time employment for both migrant groups; moderate for ES - increasing by four percentage points of the population over the decade after arrival - but large and dramatic for NES - increasing by about 15 percentage points of the NES population

The change in employment behaviour of NES immigrants is especially important. Part-time employment in the new regime increases steeply over the first six years after arrival, peaking at one in five NES migrants, an extra-ordinarily large outcome for immigrants with an average age of 35 years. After this peak, when most NES migrants have completed their tertiary education, part-time employment begins to fall quickly until ten years after arrival part-time employment is marginally above that of ES migrants, but still at higher rates than under the old regime.

The shifting pattern of employment outcomes is clear. Across regimes, all significant employment changes occur among NES migrants - the group dominated by students - and it is towards their shifting full- and part-time employment mix that we direct our attention. The large changes that are taking place have been increasing through time and to emphasize this we also compare NES outcomes for those who arrived during the latest complete five year data period, 2006-10, with outcomes from the 1981-85 inflow cohort. The later inflow data cover a shorter time period (eight years) than the 2001-2005 data, but this disadvantage is more than offset because the latest data reveal the extent of the more noticeable changes in the emerging labour market integration patterns associated with the growing importance of the two-step policy. To widen the discussion, we also divide labour force participation of both regimes into unemployment, full- and part-time employment and labour force participation and follow the changes and interactions among these series as immigrant time in Australia lengthens (Figure 5 and Figure 6).

First, on average, NES male labour force participation is 10 percentage points lower in the new regime, mostly accounted for in the early years after arrival. This is probably a student effect as a significant proportion of students will not be in the labour force at any particular time and the student share among NES immigrants has increased. The student effect is likely 
to be stronger immediately after arrival as they settle into a new country and devote most of their time to adjusting to the requirements of their education institutions. Then, as the students settle down, labour force participation will increase as they begin to direct attention to combining part-time work with study.

Second, in the early years after arrival, in both regimes, a significant gap arises between labour force participation and full-time employment as the NES labour force increases over the first few years after arrival and the full-time employment-population level is relatively constant. This increasing full-time employment - labour force participation gap, given the labour force participation definition, must be allocated to either part-time employment or to unemployment. It is the change in this allocation which is the major difference between regimes, rather than the size of the gap. The way in which the gap allocation has shifted reveals a new labour market integration process.

In the old regime, the widening gap, in the first few years after arrival, between NES labour force participation and full-time employment was filled by increased unemployment, which, within two years after arrival could increased to 20 per cent of the NES cohort population. After these initial years of high unemployment, full-time employment integration took place by drawing immigrants, more-or-less equally from the unemployment pool and from further participation increases. Part-time employment responses were relatively unimportant.

In the new regime, the widening gap, during the first few years after arrival, between labour force and full-time employment is filled by increased part-time employment and not unemployment. Within three years after arrival, part-time employment increases from a few percentage points to twenty-five per cent of the NES population cohort. Unemployment falls, as time in Australia lengthens, are relatively unimportant. It is part- time employment that falls most beginning around three or four years after arrival and as the labour market integration process continues.

When did this new labour market integration process begin to evolve? The answer is evident in Figure 7, which plots the changing ratio of part-time to total employment against months since arrival for the first, 1981-85, the middle, 1990-2000 and last, 2010-2013, NES inflow cohorts.

Under the old regime inflow, 1981-85, part-time employment accounted for just over five per cent of total NES employment and did not systematically vary with time in Australia. Fifteen years later the part-time/total employment ratio for the 1996-2000 inflow is higher and varies between a ratio of 20 and 30 per cent over the first ten years since arrival. By 2006-10, there is a further increase and now, one to four years after arrival, 40 per cent of NES immigrant employment is now employed part-time, after which part-time employment begins to fall. It is rising and falling part-time employment, rather than rising and falling unemployment that now provides the important source of full-time employment increases as time in Australia lengthens.

Finally, this paper describes a first and somewhat broad brush analysis of Labour Force data. The evolving nature of the statistical relationships are stark, certain and clearly defined. The 
evidence to support our interpretation of the reasons for these large changes, however, is very indirect and it is important to ask whether other factors could possibly replace immigration policy innovations, and the development of the two-step process, as the principal determinant of these labour market changes? Could general changes in the Australian labour market over the last four decades be the predominant reasons for these changes?

One possibility is that we are observing the effect on immigrants of the significant economywide growth of part-time jobs among all men over the last three decades. Part-time jobs now account for 17 per cent of male employment. Access to part-time jobs obviously matters but I doubt whether this is the driving force for the large differences between immigrant labour market regimes. I have three reasons in mind for this judgement (i) the rapid increase in immigrant part-time employment is primarily a NES but not an ES migrant phenomenon. Hence, aggregate part-time job growth, in isolation, cannot explain why NES migrants, and not ES migrants, have been decreasing full-time employment and increasing part-time employment. Increasing NES immigrant utilization of Australian education institutions, combined with part-time work, before applying for permanent visa status, seems a far better explanation for the new immigrant labour market outcomes. (ii) the disproportionate NES part-time job growth accelerated over the last decade and a half, at the same time that the foreign student population increased rapidly. But over this period, part-time job growth in the economy as a whole slowed. (iii) only a small fraction of the total number of part-time jobs - between one and five percent of the total - have been held by recent NES immigrant inflows. Given the small shares it is difficult to believe that shifts in the total stock of parttime jobs would exert much impact of the diversion of NES employment away from fulltime and towards part-time jobs.

Another noticeable labour market change that matters, in general, but cannot explain the pattern of migrant employment changes, is that aggregate unemployment has been lower over the last two decades, reflecting the lack of a major labour market down-turn since 1990. Falling aggregate unemployment is consistent with the large unemployment falls among NES immigrants, but is inconsistent with falling NES full-time employment and rapidly increasing NES part-time employment. Furthermore, any aggregate labour market explanation of the changes between regimes has to account for the fact that ES employment and participation rates have changed only marginally. It needs to be explained why all labour market changes have been concentrated on the NES group. ${ }^{15}$

To conclude, it should be remembered that immigration will respond to changing economic conditions in new immigrant supply countries, such as China and India. As their wealthy middle class numbers increase rapidly, and as many of these families seek overseas education, work experience and foreign country residency for their young family members it

\footnotetext{
${ }^{15}$ There have also been significant reductions in migrant access to unemployment benefits and other income support which presumably has had an impact. All immigrants arriving after January 1993 became subject to a twenty-six week waiting period for unemployment benefits. Since March 1997 there has been further tightening which has more-or-less excluded immigrants without permanent visa status from all income support programs. These restrictions apply to all immigrants and therefore cannot explain why labour market changes are concentrated on NES migrants.
} 
should be expected that they will take advantage of the new two-step immigration regime.

\section{Concluding Remarks}

The new two-step phenomenon, and the associated rapid growth of temporary immigrants with work entitlements, has many important and under-researched implications for Australia, New Zealand, Canada and other countries moving in this policy direction.

The old paradigm of immigrants as permanent settlers from the day they arrive, and the research focus on employment and earnings at arrival and their subsequent growth as measures of labour integration, needs to be revised to avoid misleading analysis. ${ }^{16}$ The labour market implications of large numbers of legal temporary immigrants with work entitlements, but no permanent status, needs to be moved closer to centre stage. In Australia, in any one year, the stock of non-permanent immigrants with work entitlements probably accounts for three or more times the labour market input of the annual intake of permanent settlers (Hugo 2006). A new paradigm is needed to address a new range of issues. ${ }^{17}$

Data collections also need to respond to the new environment. As the non-permanent immigrant work force increases in relative importance so does the intellectual and policy cost of the growing data inadequacy in this changing environment. The focus of official surveys of immigrant labour market outcomes when they receive a permanent visa seems particularly unbalanced. More information on temporary migrants and the temporary visa experience of those receiving permanent visas is needed.

Finally, what has been learnt from this preliminary analysis of the Labour Force data that is different from what has been learnt from the traditional analysis of the usual immigrant data sources?

First, over the last twenty-five years, extensive immigrant policy changes have been associated with higher employment rates for male immigrants, at the time of permanent visa receipt (Cobb-Clark, 2003). But for all male immigrant arrivals we find the opposite policy response. During the first five or so years after arrival, immigrant employment in aggregate, has been lower than a quarter of a century ago. Higher employment, at the time of permanent visa receipt, probably arises because employment is increasingly being used as a criterion for permanent visa allocation, and, at least half of new permanent visa recipients have arrived many years previously and their major labour market integration experiences, during the initial years after arrival, are excluded from official surveys of permanent immigrants (DIAC, 2012).

Second, the major change in male immigrant employment, in aggregate, has been the rapid growth of part-time employment, increasing as a share of the immigrant cohort from a peak

\footnotetext{
${ }^{16}$ For a review of the international literature that is mainly focused on the old paradigm see Aydemir (2012).

${ }^{17}$ For preliminary analysis of a new range of issues see McDonald et al (2005), Hugo (2006), Khoo et al (2008), DIAC (2012a). For an interesting macro assessment of the changing population implications of the evolving nature of Australian immigration see Cully et al (2012).
} 
of 7.5 per cent three years after arrival, 1981-1985, to 22.5 per cent, 2006-2010. Full-time employment has fallen considerably.

Third, all immigrant groups use the two-step policy framework but it is only among NES migrants - predominantly students - that the new process is noticeably impacting on labour market integration as measured by employment. The NES group is increasingly entering on student visas, accepting part-time employment while studying, and increasing the time gap between arrival in Australia and full-time employment. High NES unemployment rates, just after arrival, which were typical two and three decades ago, have been replaced by rapidly increasing part-time employment over the first three or four years after arrival. Part-time employment for male NES immigrants can now account for almost half of NES total employment three or four years after arrival.

Finally, there are interesting political economy issues that are an integral part of the twostep process that we have put aside but which make the system increasingly contentious and perhaps foreshadow large changes in the future. The allocation of visas with work entitlements for temporary immigrants has essentially been privatised and uncapped; tertiary institutions choose the number of fee-paying students and businesses choose the number of immigrants employed on a temporary basis. The allocation of permanent visas is not privatised and is capped. The political and economic implications of the tensions this system is creating will become increasingly important as the pool of temporary migrants increases (uncapped) and if government decides to reduce the permanent immigrant intake (capped). 18 This scenario would have two effects; a substantial reduction in the probability of a temporary visa holder obtaining permanent residence and few visas left for off-shore permanent visa applications. Both effects would have widespread ramifications and probably begin to reverse the trend for increasing numbers of temporary migrants.

\footnotetext{
18 One problem that has emerged is that fee paying foreign students have not been confined to universities and many students enrolled in teaching institutions that provided limited education outcomes. The immigrant then uses these institutions as a base to apply for permanent status. In the extreme, the student applies for an English language course with low academic standards, perhaps breaches the visa restrictions by working full-time and then quickly applies for permanent residence with employer sponsorship. In some instances, the course is not completed. Less extreme variants of this practice have grown quickly. In response, government has begun tightening visa access with a resultant fall in foreign fee paying student applicants (DIAC et al, Knight Review, 2011).

Another area of contention relates to the uncapped 457 business skilled employee visas. Unions and some others argue that these visas are undercutting local training. Why train a native worker if the firm can import someone already trained? There has been continuing low level tension around this scheme but the tension has increased substantially as the immigrant numbers have increased, the scope of the scheme has widened, and as aggregate economic and employment growth has been slowing.
} 


\section{References}

Australian Bureau of Statistics, ABS (2006), "Migrants; Employee Earnings, Benefits and the Trade Union Membership", Cat. no. 6310.0, Aug

Australian Bureau of Statistics, ABS (2010), "Migrants; Education and Work 2010", Cat. no. 6227.0, May

Australian Bureau of Statistics, ABS (2011), "Characteristics of Recent Migrants, Australia", Cat. no. 6250.0, Nov

Aydemir, A. (2012), "Skill Based Immigrant Selection and Labor Market Outcomes by Visa Category", IZA Discussion Paper, No 6433, March

Antecol, H., D. Cobb-Clark and S. Trejo (2003), "Immigration Policy and the Skills of Immigrants to Australia, Canada and the US", Journal of Human Resources, University of Wisconsin, Vol. 38 (1)

Birrell, B., and E. Healy (2013), "Scarce Jobs: Migrants or Locals at the end of the Queue?" Centre for Population and Urban Research, Research Report, August

Borjas, G. (1985), "Assimilation, changes in cohort quality and the earnings of immigrants", Journal of Labour Economics 3, 463-489

Breunig, R., S. Hasan and M. Salehin, (2013), "The immigrant wage gap and assimilation in Australia: does unobserved heterogeneity matter?", CEPR Discussion Paper Series, Centre for Economic Policy Research, Research School of Economics, Australian National University

Chiswick, B. R. (1978), "The Effect of Americanisation on the Earnings of Foreign Born Men”, Journal of Political Economy, Vol. 86, No. 55, 897-022

Chiswick, B. R., and P. W. Miller (2013), "Negative and Positive Assimilation By Prices and By Quantities”, IZA Discussion Paper No.7389, Study of Labor, May

Clarke, A., and M. Skuterud (2012), "Why do Immigrant Workers in Australia Perform Better than in Canada? Is it the Immigrants or their Labour Markets?", Canadian Labor Market and Skills Researcher Network, Working Paper No.96, March

Cobb-Clark, D., B. Hanel and D. McVicar (2012), "Immigrant Wage and Employment Assimilation, A comparison of Methods", IZA Discussion Paper, No 7062, Study of Labour, IZA

Cobb-Clark, D. (2003), "Public Policy and the Labour Market Adjustment of New Immigrants to Australia", Journal of Population Economics, 16:655-81

Cobb-Clark, D. (2004), "Selection Policy and the Labour Market Outcome of New Immigrants", IZA Discussion Paper, No 1380, Study of Labour IZA, November

Cully, M., and L. Pejoski (2012), “Australia unbound? Migration, openness and population futures, section 2.2, in A Greater Australia: Population, Policies and Governance, ed. G. Hugo and J. Pincus, CEDA p61-71

Department of Immigration and Citizenship, DIAC (2010), "How new migrants fare: Analysis of the Continuous Survey of Australia's Migrants", Canberra 
Department of Immigration and Citizenship, DIAC (2010a) "Obtaining a better understanding of the Student and Skilled Graduate visa programs. Final Report", Institute for Social Science Research, University of Queensland, Australian Government, Dec

Department of Immigration and Citizenship, and Department of Employment and Workplace Relations, DIAC (2011), "Strategic Review of the Student Visa Program 2011". (Knight Review), Canberra, Dec

Department of Immigration and Citizenship, DIAC (2012), “Continuous Survey of Australian Migrants, Cohorts 1-5 Report, 2009-11”, Canberra

Department of Immigration and Citizenship, DIAC (2013), “Australian Migration Trends 2011-12", Canberra

Department of Immigration and Citizenship, DIAC (2013a), “2012-2013 Migration Program Report", Canberra

Gregory, R. G. (2014), "The Changing Contribution of Female Immigrants to the Australian Labour Market (Mimeo)"

Hawthorne, L. (2008), "The Impact of Economic Selection Policy on Labour Market Outcomes for Degree Qualified Migrants in Canada and Australia", IRPP Choices, 14(5) May

Hawthorne, L. (2011), “ Competing for Skills: Migration Policies and Trends in New Zealand and Australia", IMSED Research, Report prepared for Department of Immigration and Citizenship, Australia and Department of Labour, New Zealand

Hugo, G. (2006), "Temporary Migration and the Labour Market in Australia", Australian Geographer, Aug

Junankar, P. N., S. Paul and W. Yasmeen (2010), "Are Asian Migrants Discriminated Against in the Labor Market? A Case Study of Australia", The Singapore Economic Review (SER), World Scientific Publishing Co. PTE, Ltd., Vol. 55(04), 619-646

Jackson, R. G. (1984), "Committee to Review the Australian Overseas Aid Program, Report to the Committee", Australian Government Printing Service, Canberra

Khoo, S.E., G. Hugo and P. McDonald (2008), "Which Skilled Temporary Migrants Become Permanent Residents and Why?", International Migration Review, Vol.42 No.1 Spring, P193-226

McDonald, T., and C. Worswick (1999), "The Earnings of Immigrant Men in Australia, Assimilation, Cohort Effects and Macro-economic Conditions", Economic Record, 75(228) 49-62

McDonald, P., S. Khoo and G. Hugo (2005), “Temporary Skilled Migrants' Employment and Resident Outcomes", Canberra: Department of immigration and Citizenship

Miller, P. W. (1999), "Immigration Policy and Immigrant Quality: The Australian points System", American Economic Review, American Economic Association, Vol (89), 192-197 May 
Shah, C., and G. Burke (2005), "Skilled migration: Australia", Centre for the Economics of Education and Training, Monash, Working Paper No. 63, Dec 
Figure 1 Male immigrant total employment (TE), divided by their population (P) Arrival cohorts: 1981-85 and 2001-05

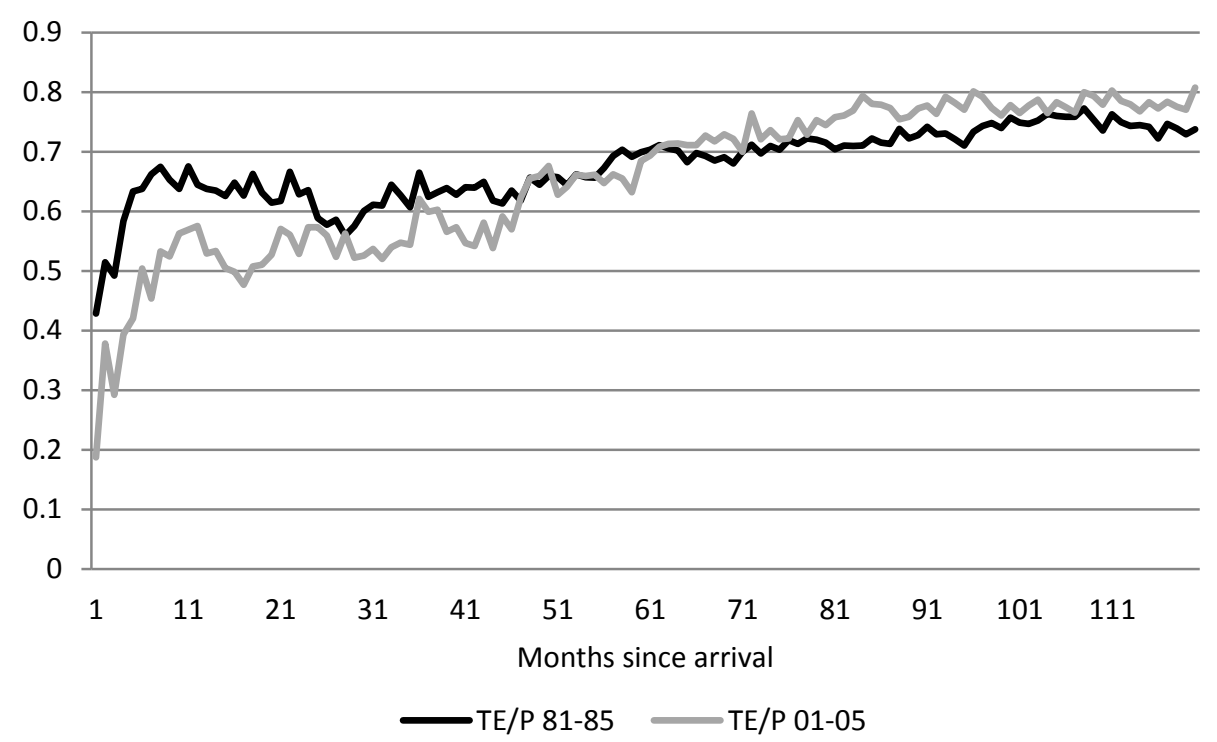

Source: ABS Labour Force, Australia, Detailed- Electronic Delivery, Dec 2013 Cat. No. 6291.0.55.001.

Figure 2 Male immigrant total employment (TE), English speaking (ES) and nonEnglish speaking (NES), divided by their respective population (PES or PNES) Arrival cohorts: 1981-85 and 2001-05

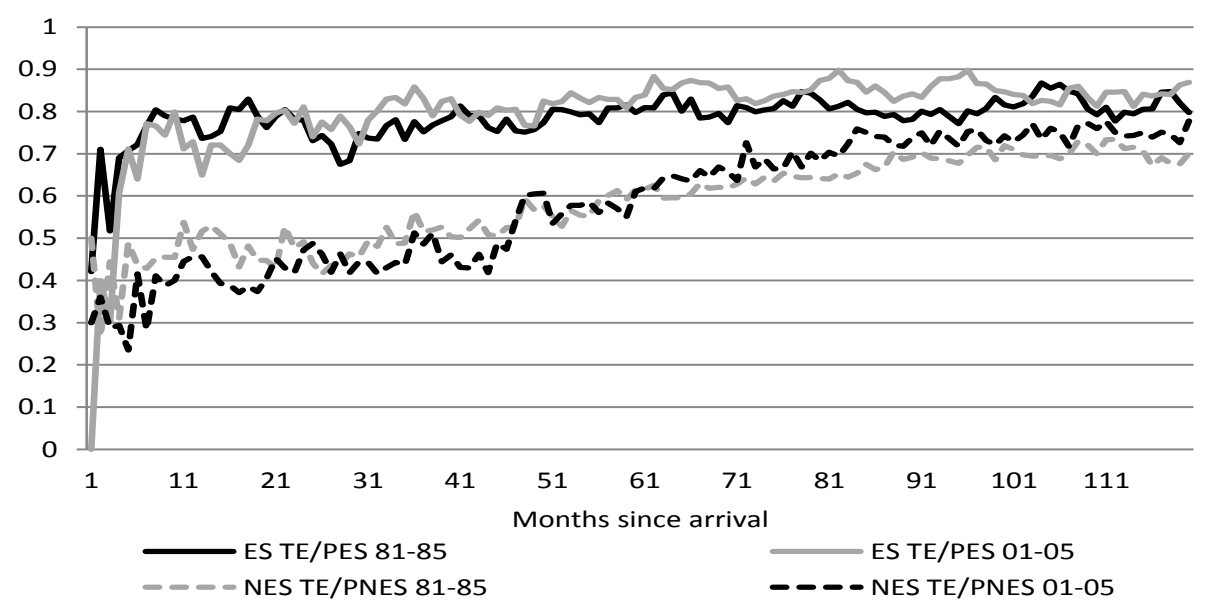

Source: As for Figure 1. 
Figure 3 Male immigrant full-time employment (FTE), English speaking (ES) and nonEnglish speaking (NES) divided by their respective population (PES or PNES)

Arrival cohorts: 1981-85 and 2001-05

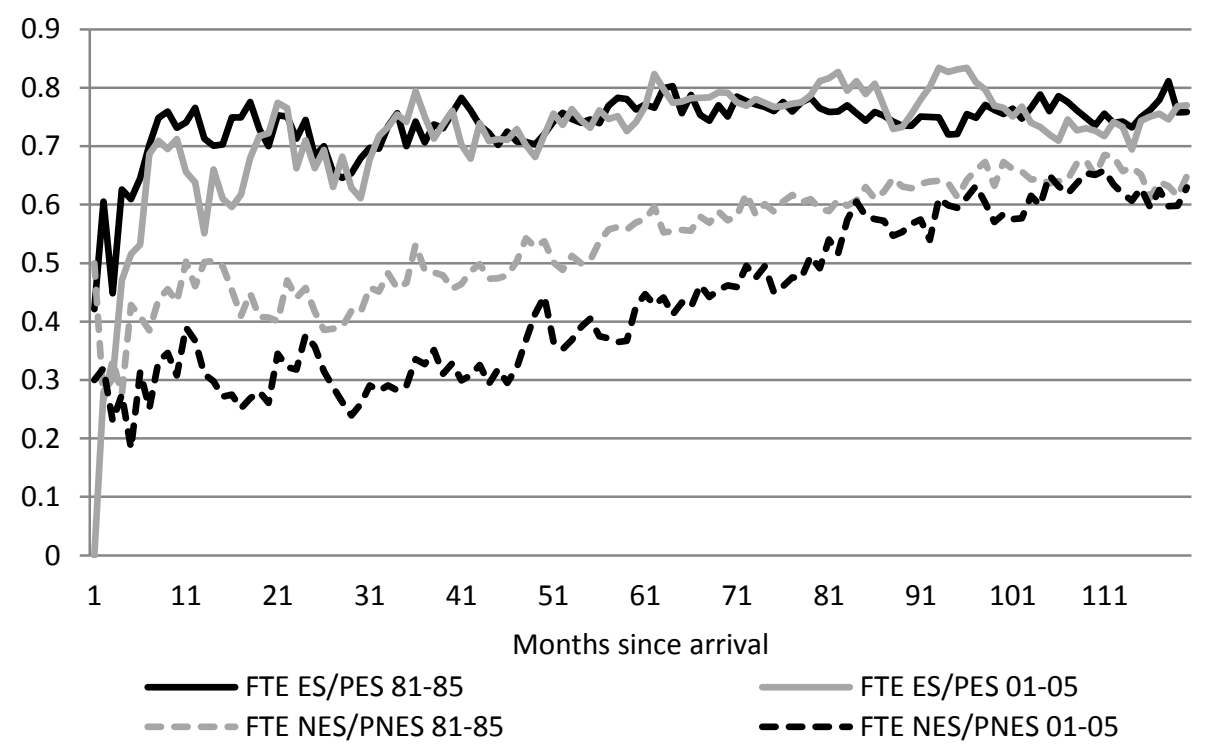

Source: As for Figure 1.

Figure 4 Male immigrant part-time employment (PTE), English speaking (ES) and nonEnglish speaking (NES), divided by their respective population (PES and PNES)

Arrival cohorts: 1981-85 and 2001-05

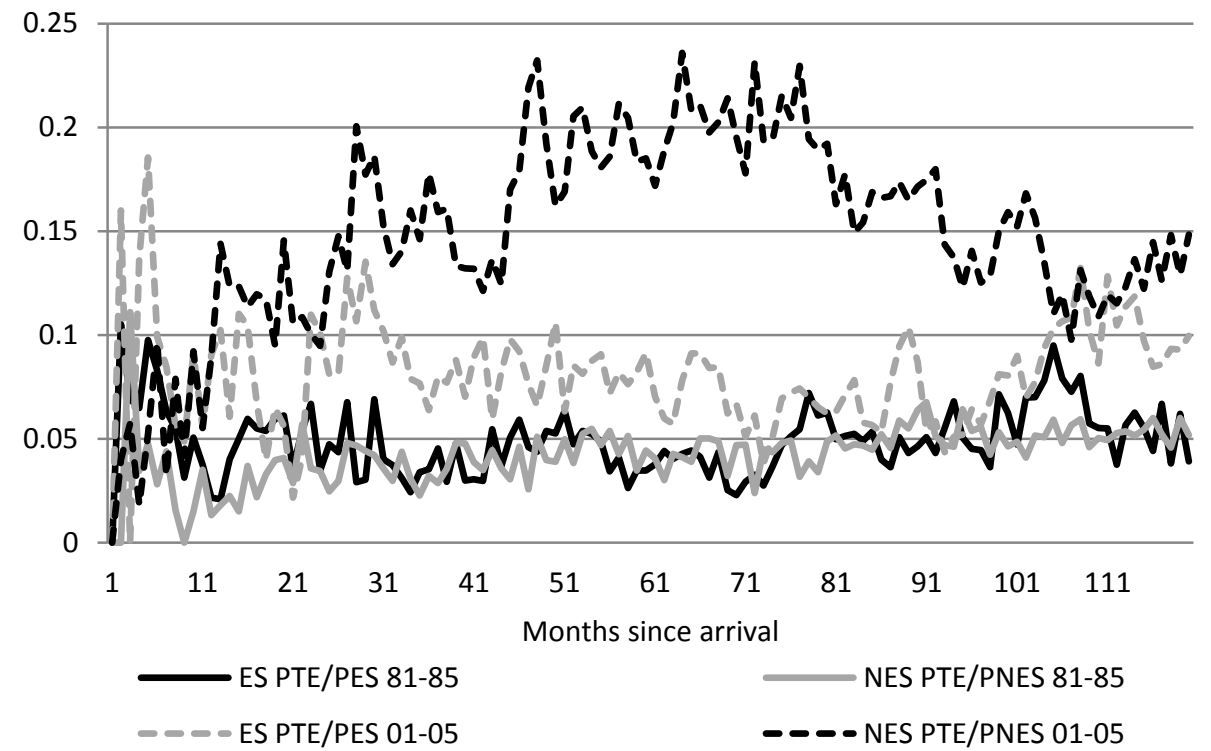

Source: As for Figure 1. 
Figure 5 Male immigrant, non-English speaking, participation rate (PR), total (TE) and full-time employment (FTE), divided by the male non-English speaking population (PNES) Arrival cohort: 1981-85

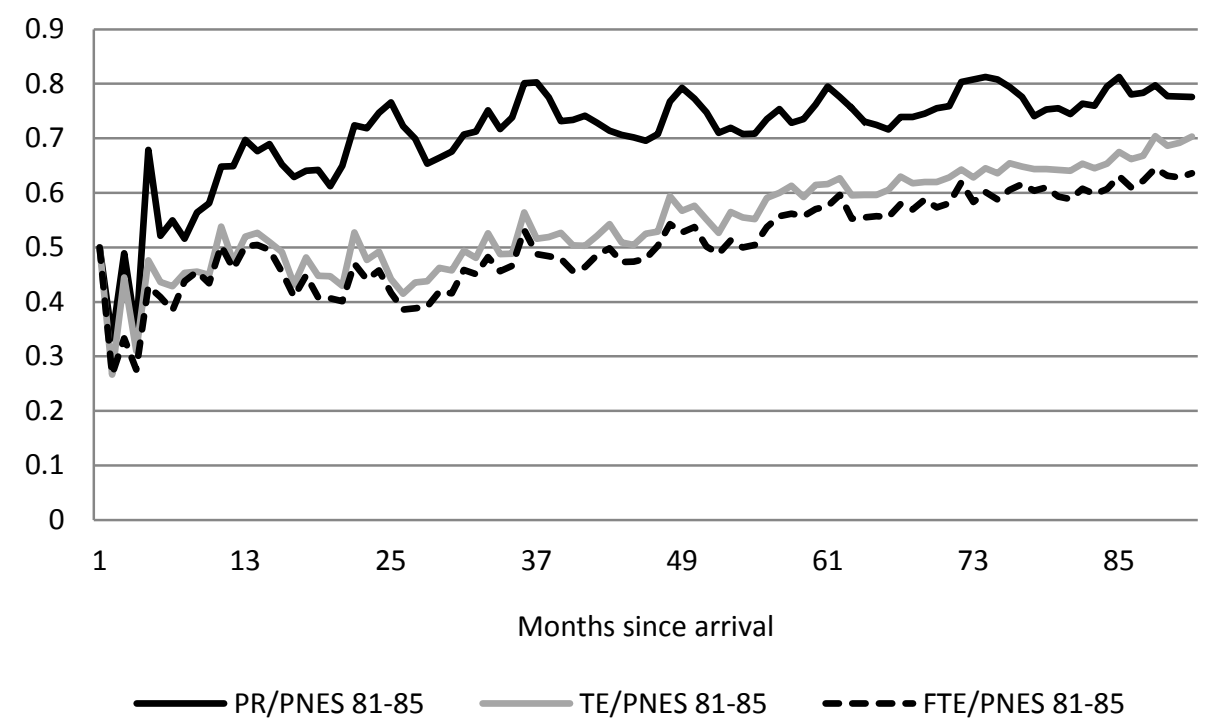

Source: As for Figure 1.

Figure 6 Male immigrant participation rate (PR), total (FTE) and full-time employment (FTE), divided by non-English speaking male immigrant population (PNES) Arrival cohort: 2006-10

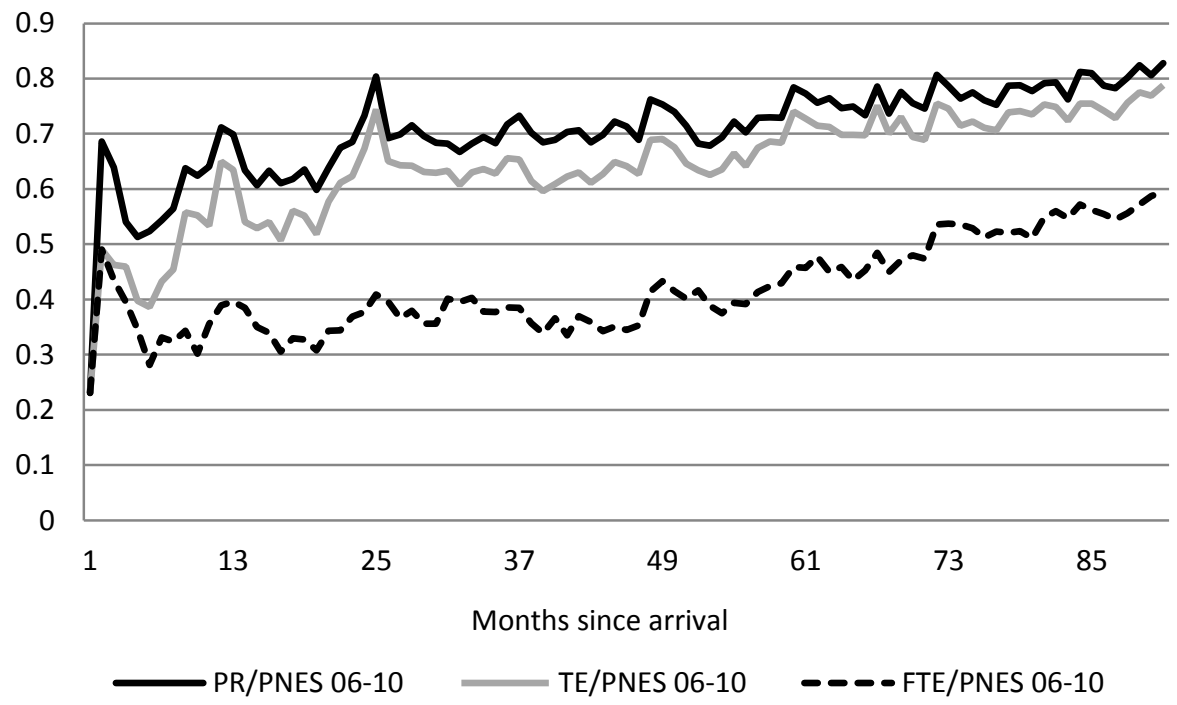

Source: As for Figure 1. 
Figure 7 Male immigrant non-speaking English (NES), part-time employment (PTE), divided by non-English speaking total employment (NES TE)

Arrival cohorts: 1981-85, 1996-2000 and 2006-10

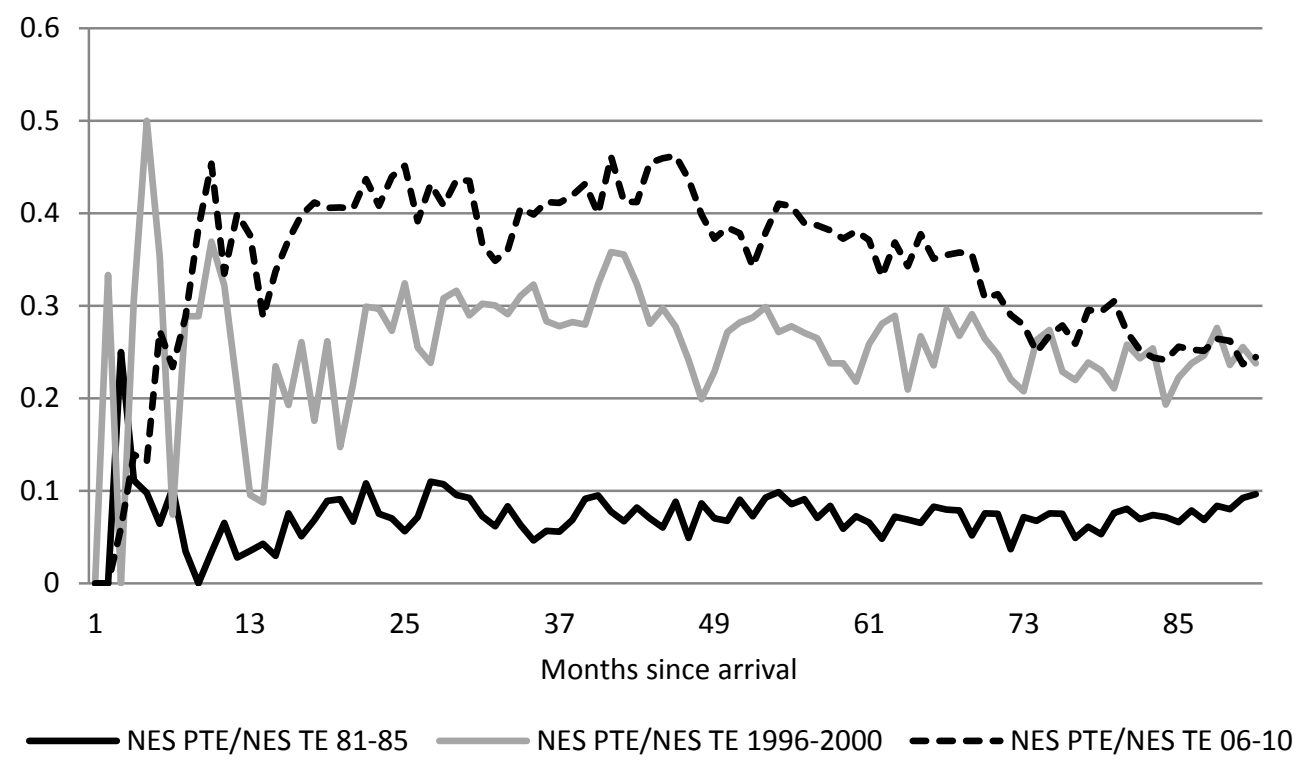

Source: As for Figure 1. 